\title{
Maternal and perinatal outcomes of induction of labor at term in the university clinics of Kinshasa, DR Congo
}

\author{
Barthélémy Tandu-Umba*, Robert Laala Tshibangu, Andy Mbangama Muela
}

Department of Obstetrics and Gynecology, University Clinics, Kinshasa, DR Congo

Email: ${ }^{*}$ btanduumba@yahoo.fr

Received 20 October 2012; revised 22 November 2012; accepted 30 November 2012

\begin{abstract}
Objective: This paper aims at assessing outcomes following induction of labor and characteristics likely to predict vaginal delivery. Study Design: This is a descriptive retrospective cohort study including all women with singleton pregnancies who delivered at term in the university clinics of Kinshasa, DR Congo, from January 01, 2006 until December 31, 2010. Induction was initiated regardless of cervical status. Methods of Induction Included: oxytocin perfusion, vaginal Misoprostol, intracervical insertion of the Foley catheter and amniotomy. Results of induction were compared in terms of failure of labor, cesarean section, fetal distress, and neonatal distress. Logistic regression was used to seek for independent contributing factors for adverse outcomes. Results: During the period of the study 115 patients at term (3.2\%)

- 39.7), and somewhat birth weight (OR 2.1 but CI containing 1). Risk for cesarean section was increased in association with induction of labor in cases of high maternal weight (OR 10.3, CI 16.0 - 67.0), and somewhat of high birth weight (OR 2.3, but CI containing 1). Fetal distress was associated only with maternal weight (OR 15.7, CI 1.3 - 187.8), and neonatal distress only with Bishop score (OR 10.9, CI 1.1 - 108.0). Conclusion Induction of labor in our setting in order to get vaginal delivery is affected of a high risk of adverse outcomes such as failure of induction, cesarean delivery, fetal and neonatal distress. This risk is significantly influenced by maternal weight, birth weight and Bishop score. Lack of worse outcomes between the first and the subsequent attempts to induce labor can be regarded as a reason to try induction even in the presence of unfavorable cervix.
\end{abstract} were concerned with induction of labor. Means for maternal age, gestational age and weight at confinement were $30.5 \pm 5.7$ years, $37.95 \pm 1.54$ weeks and $69.3 \pm 15.1 \mathrm{~kg}$, respectively. The mean parity and gravidity were $2.4 \pm 1.9$ and $2.9 \pm 1.9$, respectively. The mean Bishop score was $6.2 \pm 1.5$ at the first induction, with 66 women $(57.3 \%)$ having less than 7 . Indications for induction were: preeclampsia $(52=54.1 \%)$, premature rupture of membranes $(34=29.5 \%)$, post term $(17=14.6 \%)$, gestational diabetes $(5=4.3 \%)$, stillbirth $(5=4.3 \%)$, polyhydramnios $(3=2.6 \%)$ and cardiopathy $(1=0.8 \%)$. Methods of induction at the first attempt included: oxytocin $(86=74.7 \%)$, vaginal misoprostol $(20=17.3 \%)$, transcervical Foley catheter balloon $(14=12.1 \%)$, and amniotomy $(1=0.8 \%)$. Failure to induce uterine contraction at the first attempt was noted in 9/115 $(7.8 \%)$ women. Vaginal delivery occurred in $78(66.9 \%)$ women, and cesarean section in $34(29.6 \%)$. The majority of cesarean sections were performed at the primary induction, most of them $(29 / 34=85.3 \%)$ in women with bad Bishop score. Failure of induction was more likely to occur in association with high maternal weight (OR 6.8; CI 1.2

*Corresponding author.
Keywords: Induction of Labor; Failure of Induction; Maternal and Perinatal Outcomes; Kinshasa

\section{INTRODUCTION}

The induction of uterine contractions prior to the onset of spontaneous contractions is expected not only to achieve vaginal delivery but also to improve both maternal and perinatal outcomes in comparison with permitting pregnancy to continue [1-3]. Although studies from developed countries have been reporting induction of labor as safe [1-3], results of series from developing countries showed more cases of cesarean section and fetal distress $[4,5]$, both conditions heavily accounting for in maternal and perinatal morbi-mortality. Two main factors to be associated with safety and efficiency of induction of labor have been multiparity and a favorable cervix [2]. While multiparity is a common situation in Africa, the second factor, which probably is the most important and can be modified by mean of ripening agents, is the most missing due to high cost and questionable availability. This could explain fear and weak results of induction of labor in this area $[4,5]$. This paper aims at assessing cha- 
racteristics likely to predict maternal/neonatal outcomes of induction of labor among pregnant women at term in our maternity.

\section{METHODS}

This is a descriptive retrospective unselected cohort study including all women who delivered in our maternity of university clinics of Kinshasa, DR Congo from January 01, 2006 until December 31, 2010. Only women with singleton pregnancies at term (37 weeks gestation or more) were enrolled. Age, weight and Bishop score that have been claimed as associated with the success of labor induction $[1,2,6-8]$ were included. Previous obstetric history (scared uterus, stillbirth) and pelvic evaluation (using digital examination) permitted to exclude situations likely to precipitate a cesarean section.

Induction of labor was defined as initiation of uterine contractions prior to its spontaneous onset using either of these methods: oxytocin perfusion, vaginal Misoprostol, intracervical insertion of the Foley catheter and amniotomy. Augmentation of labor was thus excluded. Severe chronic fetal distress was excluded prior to induction using electronic assessment of fetal condition (cardiotocography). Based on the beginning of the active phase of labor failed induction of labor (FIOL) was defined as inability to achieve a cervical dilatation of $\geq 4 \mathrm{~cm}$ within $24 \mathrm{hr}$ of initiating either method [1,7].

Although cervical ripening before medical induction of labor is an important factor of the success of induction $[2,7,8]$ the policy of our department $[9,10]$ is to tempt the induction regardless of cervical status, due to unavailability and cost of ripening agents. If the membranes remain intact after a failed induction not resulting in cesarean section another attempt is scheduled in a 24-hour interval, the third attempt being the last one. Membranes that have remained intact are ruptured prior to the third (last) induction. Cesarean section was indicated within the 12 hours of labor in accordance with partograph's characteristics. Outcomes of either method of induction were compared with each other in terms of failed induction, vaginal delivery, cesarean section, fetal distress (meconium-stained amniotic fluid or heart rate disturbance), and neonatal distress (Apgar score $<7$ ). For statistic analysis chi-square calculation was used for comparing proportions. Logistic regression was used to seek for independent contribution of obstetric history (age, parity, gravidity, preterm delivery, mid-trimester loss), weight and current obstetric characteristics (gestational age, Bishop score, birth weight), indications and methods of induction on outcomes.

\section{RESULTS}

Among 3512 deliveries registered in our maternity dur- ing the period of the study 115 patients at term $(3.2 \%)$ were concerned with induction of labor. Of these, 54 were primiparae, 47 parae 2 - 4 and 14 grand multiparae. Means for maternal age, gestational age and weight at confinement were $30.5 \pm 5.7$ years, $37.95 \pm 1.54$ weeks and $69.3 \pm 15.1 \mathrm{~kg}$, respectively. The mean parity and gravidity were $2.4 \pm 1.9$ and $2.9 \pm 1.9$, respectively. The mean Bishop score was $6.2 \pm 1.5$ at the first induction, with 66 women $(57.3 \%)$ having less than 7 .

Indications for induction were: preeclampsia $(52=$ $54.1 \%)$, premature rupture of membranes $(34=29.5 \%)$, post term $(17=14.6 \%)$, gestational diabetes $(5=4.3 \%)$, stillbirth $(5=4.3 \%)$, polyhydramnios $(3=2.6 \%)$ and cardiopathy $(1=0.8 \%)$. Methods of induction at the first attempt included: oxytocin $(86=74.7 \%)$, vaginal misoprostol $(20=17.3 \%)$, transcervical Foley catheter balloon $(14=12.1 \%)$, and amniotomy $(1=0.8 \%)$. When all the attempts (125) were considered, these proportions turned to $88 / 125$ (70.4\%), 25/125 (20\%), 14/125 (11.2\%), and $1 / 125(0.8 \%)$ respectively (Table 1$)$.

Failure to induce uterine contraction at the first attempt was noted in $9 / 115(7.8 \%)$ women, which represents the majority of the overall 10 cases observed during the study period. It was observed mostly after use of oxytocin, but cesarean section was more frequent with Foley catheter $(6 / 14=42.9 \%)$ than with misoprotol $(6 / 25=$ $24 \%)$ and oxytocin infusion $(22 / 88=25 \%$ ) (Table 2). No significant difference was found (chi-square).

Vaginal delivery occurred in $78(66.9 \%)$ women, and cesarean section in 34 (29.6\%). The majority of cesarean sections were performed at the primary induction, most of them $(29 / 34=85.3 \%)$ in women with bad Bishop score. Of 78 vaginally delivered $66 / 115$ cases $(67.8 \%)$ had a good Bishop score.

As of indications of cesarean section, the leading cause was fetal distress $(13 / 34=38.2 \%)$, followed by failure of induction in preeclamptic women $(9 / 34=$ $26.5 \%)$ and fetopelvic disproportion $(6 / 34=17.6 \%)$. Of 34 cesarean sections fetal distress was encountered in 8 cases with oxytocin $(23.5 \%), 3$ with misoprostol $(8.8 \%)$, 3 with Foley catheter $(8.8 \%)$, and $2(5.8 \%)$ with amniotomy. Apgar score $<7$ at the first minute occurred in $29 / 115(25.2 \%)$ children. No significant difference was found (chi-square).

Furthering calculations (logistic regression analysis) to possible impact of obstetric history, maternal weight, current obstetric characteristics, indications and methods of induction on maternal and neonatal outcomes showed significant results for maternal weight, birth weight and Bishop score (Table 3). So risk for cesarean section was increased in association with induction of labor in cases of high maternal weight (OR 10.3, CI 16.0 - 67.0), and somewhat of high birth weight (OR 2.3, but CI containing 1). Failure of induction was more likely to occur in 
Table 1. Total attempts according to methods of induction.

\begin{tabular}{ccccccc}
\hline & Oxytocin & Misoprostol & Foley & Amniotomy & Total \\
\hline First induction & 82 & 20 & 14 & 1 & - & 115 \\
Second induction & 6 & 3 & - & - & - & 9 \\
Third induction & - & 1 & - & - & 1 \\
\hline
\end{tabular}

Table 2. Maternal outcomes according to methods used.

\begin{tabular}{|c|c|c|c|c|c|c|c|c|c|c|c|c|c|}
\hline \multirow{2}{*}{ Outcome } & \multicolumn{4}{|c|}{ First induction } & \multicolumn{4}{|c|}{ Second induction } & \multicolumn{4}{|c|}{ Third induction } & \multirow{2}{*}{ Total } \\
\hline & Ox & Mis & Fol & Amn & Ox & Mis & Fol & Amn & Ox & Mis & Fol & Amn & \\
\hline Vaginal delivery & 51 & 13 & 8 & 1 & 6 & 3 & 0 & 0 & 0 & 0 & 0 & 0 & 82 \\
\hline Cesarean section & 22 & 5 & 6 & 0 & 0 & 0 & 0 & 0 & 0 & 1 & 0 & 0 & 34 \\
\hline FIOL & 9 & 0 & 0 & 0 & 0 & 0 & 0 & 0 & 0 & 1 & 0 & 0 & 10 \\
\hline Total & 82 & 18 & 14 & 1 & 6 & 3 & 0 & 0 & 0 & 1 & 0 & 0 & 125 \\
\hline
\end{tabular}

$\mathrm{Ox}=$ Oxytocin $;$ Mis = Misoprostol; Fol = Foley catheter; Amn = Amniotomy.

Table 3. Significant relation between maternal/neonatal characteristics and outcomes of induction.

\begin{tabular}{|c|c|c|c|c|c|}
\hline & & $\begin{array}{c}\text { Cesarean } \\
\text { section }\end{array}$ & $\begin{array}{l}\text { Fail of } \\
\text { induction }\end{array}$ & $\begin{array}{c}\text { Fetal } \\
\text { distress }\end{array}$ & $\begin{array}{c}\text { Neonatal } \\
\text { distress }\end{array}$ \\
\hline \multicolumn{6}{|l|}{ Characteristics } \\
\hline $\begin{array}{c}\text { Maternal } \\
\text { weight }\end{array}$ & $\begin{array}{c}\mathrm{P} \\
\text { OR } \\
\text { CI }\end{array}$ & $\begin{array}{c}0.01 \\
10.3 \\
16.0-67.0\end{array}$ & $\begin{array}{c}0.04 \\
6.8 \\
1.2-39.7\end{array}$ & $\begin{array}{c}0.03 \\
15.7 \\
1.3-187.8\end{array}$ & $\begin{array}{l}- \\
- \\
-\end{array}$ \\
\hline Birth weight & $\begin{array}{c}\mathrm{P} \\
\text { OR } \\
\text { CI }\end{array}$ & $\begin{array}{c}0.3 \\
2.3 \\
0.2-29.0^{*}\end{array}$ & $\begin{array}{c}0.04 \\
2.1 \\
0.17-26.3^{*}\end{array}$ & $\begin{array}{l}- \\
- \\
-\end{array}$ & $\begin{array}{l}- \\
- \\
-\end{array}$ \\
\hline Bishop score & $\begin{array}{c}\mathrm{P} \\
\mathrm{OR} \\
\mathrm{CI}\end{array}$ & $\begin{array}{l}- \\
- \\
-\end{array}$ & $\begin{array}{l}- \\
- \\
-\end{array}$ & $\begin{array}{l}- \\
- \\
-\end{array}$ & $\begin{array}{c}0.01 \\
10.9 \\
1.1-108.0\end{array}$ \\
\hline
\end{tabular}

${ }^{*} \mathrm{CI}$ contains 1 .

association with high maternal weight (OR 6.8; CI 1.2 39.7), and somewhat birth weight (OR 2.1 but CI containing 1). Fetal distress was associated only with maternal weight (OR 15.7, CI 1.3 - 187.8), and neonatal distress only with Bishop score (OR 10.9, CI 1.1 - 108.0).

\section{DISCUSSION}

The rate of induction reported in our series (3.2\%) does not represent the overall issue of induction of labor in our setting since it excludes pregnancies lower than 37 weeks gestation. However, it is much lower than that of up to $20 \%$ in series of developed countries [1-3]. A recent WHO Global Survey dealing with determinants of use of induction of labor in Africa [11] found an average rate of induction ranging from $1.4 \%$ to $6.8 \%$ (5.1\% for DR Congo). It pointed out social reasons (place of residence, duration of schooling, type of health facility and level of antenatal care) to explain unmet need for induction of labor. In our mind reluctance to use such a worldwide accepted practice might also be owed to fear of failure and complications that have been reported in Africa $[4,5]$ when compared with spontaneous labor.

Only 66/115 women $(42.7 \%)$ of our series had a Bishop score $\geq 7$ at the first induction, meaning a prediction of a low success rate of labor induction [6-8]. Occurrence of vaginal delivery in $78 / 115(66.9 \%)$ women can thus be regarded as a reason to try induction even in the presence of unfavorable cervix. Previous studies in our setting [9] have experienced that successive attempts contribute to ripening the cervix. Lack of worse outcomes between the first and the subsequent attempts of induction could be owed both to this cumulative ripening effect and to the fact that most cases resulting into cesarean section occurred at the first attempt, the majority in women with bad Bishop score. This means that unfavorable cervix remains a condition likely to lead to cesarean section.

The rates of fetal/neonatal distress $(25 \%)$ and cesarean section (near 30\%) of our series are higher than that of the overall obstetric population in our maternity in 2010 (16\% and $24 \%$, respectively), meaning more risks than reported in series from developed countries [2,3] where induction of labor at term has lower odds of cesarean section as well as of fetal/neonatal distress than expectant management of pregnancy. Beckmann [11] additionally found that the length of latent phase may influence mode of birth during induction with oxytocin but this was not assessed in our study.

Our study pointed out three factors mainly accounting for in risk for failure of induction, cesarean section, and fetal and neonatal distress in our setting: maternal weight, 
fetal weight to which it is expectedly linked and Bishop score whose bad record would be worsened by the formers. Park [12,13] demonstrated that fetal weight was among additional factors to initial cervical length that significantly contribute to arrest disorder during the active phase and second stage of labor in nulliparous.

The strength of our study is to have addressed the issue of risks and benefits of induction of labor in terms of failure of induction as well as of maternal and fetal/ neonatal outcomes. One of the weaknesses of our study could be the underreporting of treatment options of obstetrical situations likely to be associated with the decision of a cesarean section, which could be accounted for as confounding factors [14]. Another one could be related to likelihood of delay in initiation of contractions beyond the interval of 24 hours, leading to a false definition of failure of induction.

\section{CONCLUSION}

Induction of labor in our setting in order to get vaginal delivery is affected of a higher risk of failure of induction, cesarean delivery, fetal and neonatal distress. This risk is significantly influenced by maternal weight, birth weight and Bishop score. Lack of worse outcomes between the first and the subsequent attempts to induce labor can be regarded as a reason to try induction even in the presence of unfavorable cervix.

\section{REFERENCES}

[1] Xenakis, E.M.-J., Piper, J.M., Conway, D.L. and Langer, O. (1997) Induction of labor in the nineties: Conquering the unfavorable cervix. Obstetrics \& Gynecology, 9, 235239. doi:10.1016/S0029-7844(97)00259-7

[2] Caughey, A.B., Sundaram, V., Kaimal, A.J., Cheng, Y.W., Gienger, A., Little, S.E., et al. (2009) Maternal and neonatal outcomes of elective induction of labor. AHRQ Publication No. 09-E005, Evidence Report/Technology Assessment, 9, 1-257.

[3] Stock, S.J., Ferguson, E., Duffy, A., Ford, I., Chalmers, J. and Norman, J.E. (2012) Outcomes of elective induction of labour compared with expectant management: Population based study. British Medical Journal, 344, e2838. doi:10.1136/bmj.e2838

[4] Fofie, C.O. and Baffoe, P. (2010) A two-year review of uterine rupture in a regional hospital. Ghana Medical Journal, 44, 98-102.
[5] Nyengidiki, T.K. and Allagoa, D.O. (2011) Rupture of the gravid uterus in a tertiary health facility in the Niger delta region of Nigeria: A 5-year review. Nigerian Medical Journal, 25, 230-234. doi:10.4103/0300-1652.93794

[6] Vikram, T.S. and Sabaratnam, A. (2011) Failed induction of labor: Strategies to improve the success rates. Obstetrical \& Gynecological Survey, 66, 717-728. doi:10.1097/OGX.0b013e31823e0c69

[7] Park, K.H., Hong, J.S., Shin, D.M. and Kang, W.S. (2009) Prediction of failed labor induction in parous women at term: Role of previous obstetric history, digital examination and sonographic measurement of cervical length. Journal of Obstetrics and Gynaecology Research, 35, 301-306. doi:10.1111/j.1447-0756.2008.00929.x

[8] Crane, J.M. (2006) Factors predicting labor induction success: A critical analysis. Clinical Obstetrics and Gynecology, 49, 573-584. doi:10.1097/00003081-200609000-00017

[9] Tandu-Umba, N.F.B., Pentuala, N.F. and Sengeyi, M.A.D. (2000) Induction of labor by oxytocin without cervix ripening: Experience of the university clinics of Kinshasa. Congo Médical, 2, 911-914.

[10] Kangudia, M.J. (2000) Comparative study of three protocols of induction of labor: Foley catheter, oxytocin, and misoprostol. Mémoire, Faculty of medicine, University of Kinshasa, Kinshasa.

[11] Fawole, B., Nafiou, I., Machoki, M., Wolomby-Molondo, J.J., Mugerwa, K., Neves, I., et al. (2012) Unmet need for induction of labor in Africa: Secondary analysis from the 2004-2005 WHO global maternal and perinatal health survey. BMC Public Health, 12, 722-738. doi:10.1186/1471-2458-12-722

[12] Beckmann, M. (2007) Predicting a failed induction. Australian and New Zealand Journal of Obstetrics and Gynaecology, 47, 394-398. doi:10.1111/j.1479-828X.2007.00763.x

[13] Park, K.H. (2007) Transvaginal ultrasonographic cervical measurement in predicting failed labor induction and cesarean delivery for failure to progress in nulliparous women. Journal of Korean Medical Science, 22, 722-727. doi:10.3346/jkms.2007.22.4.722

[14] Tajik, P., van der Tuuk, K., Koopmans, C.M., Groen, H., van Pampus, M.G., van der Berg, P.P., et al. (2012) Should cervical favorability play a role in the decision for labor induction in gestational hypertension or mild preeclampsia at term? An exploratory analysis of the Hypitat trial. International Journal of Obstetrics and Gynaecology, 119, 1123-1130. doi:10.1111/j.1471-0528.2012.03405.x 